\title{
RELAÇÕES DE GÊNERO ATRAVÉS DE OFICINAS TEMÁTICAS: USOS E ABUSOS DA HISTÓRIA
}

\section{GENDER RELATIONS THROUGH THEMATIC WORKSHOPS: USES AND ABUSES OF HISTORY}

\author{
Ana Carolina Eiras Coelho Soares ${ }^{1}$ \\ Suellen Resende de Peixoto ${ }^{2}$
}

\begin{abstract}
RESUMO
O presente artigo busca relacionar a importância da experiência de três oficinas temáticas relacionadas aos Estudos de gênero com o ensino de História nas escolas brasileiras. Todas as oficinas foram realizadas em 2018 dentro do eixo temático "Educação e Diversidade" e tiveram algum aspecto relacionado com as questões de gênero na Educação: "Literatura de Cordel", "Leodegária de Jesus e Poesia Visual" e "Educação Holística: Gênero, Educação e Diversidade". Descrever e analisar a experiência pessoal docente, a fim de compreender a experiência cultural relacionada dialogicamente às contribuições das análises de Gênero, implica em contribuir para a interdisciplinaridade necessária entre os campos da História e da Pedagogia e construir um espaço escolar que trilhe possibilidades de se tornarem espaços com maior equidade de gênero.
\end{abstract}

Palavras-chaves: História. Pedagogia. Relações de gênero. Oficinas temáticas. Educação.

\section{ABSTRACT}

This article seeks to relate the importance of the experience of three thematic workshops related to Gender Studies with the history teaching in Brazilian schools. All the workshops were held in 2018 within the themes "Education and Diversity" and had some

\footnotetext{
1 Professora Associada do Programa de Pós-Graduação em História da Faculdade de História da Universidade Federal de Goiás. Doutora, Mestra e Licenciada/Bacharel em História pela Universidade do Estado do Rio de Janeiro, possui especialização em Psicopedagogia pela UCAM/RJ e realizou estágio de pós-doutoramento entre 2015/2017 em Antropologia no DAN/UNB com apoio FAPEG/CAPES. Atualmente está Coordenadora do GT Regional de Gênero da ANPUH (Associação Nacional de História) - Goiás; Coordenadora do Grupo de Estudos e Pesquisas em Gênero/FH-UFG/CNPq. Possui experiência na área de História, com ênfase em estudos sobre a imprensa, literatura, feminismos e sexualidades, atuando principalmente nos seguintes temas: história cultural, gênero, mulheres, violência, literatura, sexualidades, século XIX e XX, José de Alencar e Brasil. Mãe de duas crianças, esteve em licença maternidade em 2011 e 2017/2018.

${ }^{2}$ Doutoranda em História pelo PPGH da UFG. Mestre em História pela UFG na linha de pesquisa Fronteiras, Interculturalidades e Ensino de História.Pesquisadora no Grupo de Extensão e Pesquisa em Estudos de Gênero- UFG (GEPEG). Especialista em História Cultural pela UFG. Aperfeiçoamento em História Indígena pela UFSJ. Graduada em História e Pedagogia. Atualmente é docente convidada na UEG Campus Itaberaí, na Pós Graduação em Docência na Educação Infantil e Anos Iniciais: Currículo, Diversidade e Tecnologias ministrando no módulo de Gênero e Diversidade do curso de Pedagogia. Atuou como Docente na Graduação de Pedagogia da Fan Padrão.Docente de História Étnico- racial da Faculdade Suldamérica para o curso de Administração e Ciências Contábeis.Coordenadora da Comissão Própria de Avaliação da Faculdade Suldamérica. Experiências na área de Pedagogia (Alfabetização e Letramento, Metodologias Ativas, Planejamento e Avaliação, Políticas Educacionais, Metodologia do Ensino de História, História da Educação I e II). No Ensino Médio, atuou com as disciplinas: Geopolítica, Sociologia e Filosofia. Atualmente é Docente no Colégio de Aplicação Alfredo Nasser no Ensino Fundamental II fase.
} 
Dossiê: Ensino de História, História das Mulheres e Desigualdades Sociais no Brasil

aspect related to gender issues in Education: "Cordel's Literature", "Jesus' Lecture and Visual Poetry" and "Holistic Education: Gender, Education and Diversity". To describe and analyze the personal teaching experience, in order to understand the cultural experience dialogically related to the contributions of Gender analysis, implies contributing to the necessary interdisciplinarity between the fields of History and Pedagogy so that it is possible to build a school space that offers the possibility of becoming a space with greater gender equity.

Key words: History. Pedagogy. Gender relations. Thematic workshops. Education.

Docentes de História são principalmente construtoras/es de histórias. A fantástica jornada de planejar, criar e executar atividades didáticas que promovam reflexões, debates e mudanças no corpo discente compõe uma das imensas alegrias de exercer o ofício da Educação. Somos alimentadas/os pelos sonhos de dias mais justos, de pessoas mais críticas e de futuros melhores a cada dia que nosso plano de aula "funciona" e, em todo debate em que percebemos o crescimento e o aprofundamento das análises das pessoas que estão sob nossa responsabilidade de ensino. O material "ser humano" nos inspira e nos incita, a cada manhã, à busca por novos caminhos pedagógicos e formas de atuação nos espaços de saberes institucionais.

Se você pretende mudar alguma coisa de sua própria prática pedagógica cotidiana, você precisa ir repensando as concepções que estão por trás dela e, concomitantemente ir alterando seu dia-a-dia em sala de aula. Não espere saber tudo sobre todas as concepções existentes. Se você quer mesmo mudar algo, é preciso que você se pense e se apresente aos seus alunos como alguém que sabe o que é mais importante para um professor: levar seus alunos a aprender a estudar e, para um professor de história, levar seus alunos a fazer uma reflexão de natureza histórica. (CABRINI, CIAMPI, VIEIRA, PEIXOTO e BORGES, 1994, p. 15-16)

O presente artigo discute as reflexões oriundas de uma experiência de um evento pedagógico que culminou em três Oficinas voltadas para as temáticas dos "estudos de gênero, educação e diversidade" em uma instituição particular de ensino superior da periferia de Goiânia. As experiências vividas aconteceram em 2018, nas oficinas promovidas pela Semana Acadêmica de Pedagogia, intitulada pela instituição como "Projeto de Leitura". A proposta tinha como foco promover diferentes leituras de mundo e experiências com temáticas variadas que envolvesse a Educação. 
Dossiê: Ensino de História, História das Mulheres e Desigualdades Sociais no Brasil

Considerando a importância das oficinas pedagógicas como ferramenta didática, tal arcabouço metodológico contribui para a interlocução de saberes práticos e científicos na formação dos profissionais de educação, incorporando a reflexão crítica como possibilidade afirmativa na construção de conhecimento e na transformação dos espaços educacionais. Assim:

Uma oficina é, pois, uma oportunidade de vivenciar situações concretas e significativas, baseada no tripé: sentir-pensar-agir, com objetivos pedagógicos. Nesse sentido, a metodologia da oficina muda o foco tradicional da aprendizagem (cognição), passando a incorporar a ação e a reflexão. Em outras palavras, numa oficina ocorrem apropriação, construção e produção de conhecimentos teóricos e práticos, de forma ativa e reflexiva (PAVIANI \& FONTANA, 2009, p. 78).

A professora condutora dessas oficinas é formada em História e Pedagogia e, atualmente doutoranda em História, e compreendemos que a oportunidade de lecionar em um curso de Pedagogia no ensino superior da periferia de Goiânia, possibilitou um percurso analítico autorreflexivo sobre a percepção entre as interseções práticas, necessárias e fundamentais, entre os campos dos estudos de Gênero, Educação e História. Como na ocasião a instituição permitiu que cada docente tivesse a liberdade para sugerir uma proposta, a escolha foi promover Oficinas com a temática: Gênero, Educação e Diversidade, o que possibilitaria a interseção com o campo da História em sua execução. Com três aulas semanais, a divisão da temática se configurou a partir dos tópicos: "Literatura de Cordel", "Leodegária de Jesus e Poesia Visual" e "Educação Holística: Gênero, Educação e Diversidade".

Majoritariamente composta por mulheres de diferentes idades, crenças religiosas, culturas e etnias, e contando com apenas dois únicos homens no referido curso, pretendemos refletir sobre a relação dessas oficinas com o corpo discente. Ao tecer a narrativa sobre essas experiências fomos incitadas a novas reflexões sobre as assimetrias orquestradas em discursividades violentas e androcêntricas, legitimadas pela cultura. De acordo com Bourdieu:

[...] violência simbólica, violência suave, insensível, invisível a suas próprias vítimas, que se exerce essencialmente pelas vias puramente simbólicas da comunicação e do conhecimento, ou, mais precisamente, do desconhecimento, do reconhecimento ou, em última instância, do sentimento (BOURDIEU, 2002, p.0203) 
A partir desse (re)olhar docente sobre a experiência didática vivida foi possível observar formas de linguagem verbais e não verbais, associadas a estereótipos arraigados que foram intensamente discutidos e debatidos. Incorporar as discussões sobre as questões dos estudos de Gênero a uma história dialógica parte da ideia de que é preciso pensar a história de uma maneira integrada, e o grande desafio foi propor essa interlocução de campos no curso de Pedagogia. A proposta foi tratada, ao ser apresentada para a equipe diretiva da instituição, como sendo algo "ousado" e "inovador", porém embora hesitantes, não houve vetos à sua execução.

Além disso, o tema foi igualmente recebido com algum estranhamento pelo corpo discente. Gradativamente, no entanto, ao longo da Semana de Pedagogia, as parcas inscrições para as oficinas tornaram-se tão surpreendentemente volumosas que, ao final do evento, foi o tema que teve mais inscritos. Ressaltamos, inclusive, como ponto positivo de nossa avaliação desse formato didático estratégico, a necessidade de realocação física para a execução das oficinas para uma sala maior que pudesse acomodar todas as pessoas interessadas em participar.

Felizmente, houve também o interesse pessoal e a participação dos dois únicos homens cisgêneros do curso de Pedagogia - respectivamente do quarto e sexto períodos na época - que se motivaram pela oportunidade de problematizar uma narrativa histórica, que delineia exclusões ou permanências androcêntricas. Nesse sentido, as oficinas propõem discutir também as estruturas sociais desiguais que atingem homens e mulheres de diferentes maneiras. Antes mesmo das ações pedagógicas preparadas para as Oficinas de Gênero, os dois acadêmicos compartilharam em grupo, numa roda de conversa, as grandes dificuldades de pedagogos encontrarem emprego na prática de estágio. Um dos efeitos das ações foi, portanto, refletirmos que as oficinas devem tê-los instigado a questionar sobre suas próprias condições de trabalho e escolhas profissionais. A quebra dos paradigmas tradicionais dos papéis de gênero interlaça na prática cotidiana a estranheza de ocupar um espaço construído como historicamente feminino. 


\section{HISTÓRIA}

Dossiê: Ensino de História, História das Mulheres e Desigualdades Sociais no Brasil

A desconstrução, ou o tornar evidente a historicidade dos conceitos postos como verdades, sob todas as lógicas binária que atravessam os discursos de gênero e moldam as verdades sobre as/os sujeitas/sujeitos na História, é uma das primeiras discussões realizadas pelas pessoas que se interessam em estudar relações de gênero. Dentro de um curso de pedagogia, a discrepância no corpo discente permitiu essa problematização, uma vez que a lógica binária que relega a Pedagogia, atualmente, à esfera das atividades ditas "femininas" possui uma história. A professora pedagoga, plena de amor, cuidado e sacralização maternal constituiu uma barreira explicita nas dificuldades contemporâneas da empregabilidade dos homens que cursam pedagogia. Para Louro (2006), as verdades construídas sobre a estruturas hetero/homossexuais, devem ser analisadas pela ótica do poder e diferença.

Poder e diferença constituem-se, portanto, em questões absolutamente relevantes na ótica que privilegiamos. Os processos de constituição de uma prática sexual como normal (e, então, como a prática a ser compulsoriamente adotada por todos) e de outras práticas como desviantes ou anormais se dá em meio e por meio de jogos de poder. Para se compreender como se constituem identidades e práticas sexuais bem como para perceber a "força" e eficiência de pedagogias culturais da sexualidade (maciçamente exercidas na direção da heterossexualidade) de pouco serviria, contudo, pensar o poder unidirecional, centralizado e meramente repressivo; provavelmente será mais útil pensá-lo disseminado, multifacetado e produtivo. Teríamos que operar com a ideia de jogos no plural nos quais poder e resistência se exercitam, jogos nos quais se instituem referências de normalidade ou diferença, de sujeitos normais e de sujeitos "diferentes". (LOURO, 2006, p.04-05)

Pensando nos símbolos culturais estabelecidos dentro de estruturas sexistas, a articulação das/os sujeitas/os como agentes sociais na práxis humana, dependerá do conjunto de posições sociais da/o sujeita/o e da multiplicidade de relações sociais nas quais ele está inscrito como agente social (AUAD, 2006). As práticas pedagógicas estabelecidas na temática de Gênero, desenvolveram múltiplas experiências transformadoras de caráter subjetivo e emancipatório. 


\section{HISTÓRIA}

Dossiê: Ensino de História, História das Mulheres e Desigualdades Sociais no Brasil

\section{Oficina 1: A Lei Maria da Penha em Cordel}

Com o título da semana pedagógica: Projeto de Leitura e a oportunidade de entender a história das relações de gênero como projetos de poder - por meio dos silenciamentos e apagamentos das mulheres na História - foi proposta, primeiramente, uma oficina sobre a literatura de cordel e violências contra as mulheres e de gênero, através da apresentação e debate sobre o vídeo "A lei Maria da Penha em Cordel"3, que apresenta a legislação sobre a violência contra a mulher nesse formato literário. Acerca da importância do cordel e seu caráter subjetivo, Mendes afirma:

Com relação ao cordel, esse "tom", que nos revela a imagem de si do poeta, é compassado por um ritmo, cujo corpo vocal também nos ajuda reconhecer/ incorporar/experienciar o ethos que o poeta constrói em seu discurso. [...] Podemos notar que, se relacionarmos um conjunto de elementos internos e externos à situação comunicativa como, por exemplo, as nossas representações sociais associadas ao ritmo e ao corpo (gestos, expressões, etc.), é possível participarmos desse processo de incorporação da imagem de si que o poeta projeta em seu

Foi possível, por meio dessa literatura, propiciar na oficina uma análise reflexiva acerca da violência contra a mulher e seus meandros familiares. Muitos foram os sorrisos, mas também a percepção pelo cordel que viabilizou a informação de violências que muitas sofriam sem perceber.

A forma descontraída de Tião Simpatia manejada pela melodia exacerbou memórias das regiões sertanejas de muitas mulheres que não tiveram acesso igualitário a uma educação equitativa, e sobretudo, fizeram-nas perceber o grande paradigma quebrado em suas próprias famílias, por serem, várias delas, as primeiras mulheres a se formarem em um curso superior no Brasil no século XXI. As desigualdades de gênero que pareciam teorias tão distantes ganharam voz, corpo e prática aos olhos dessas mulheres, algumas já mães e avós, outras ainda jovens. Como bem afirma Connel (2016, p.17)

\footnotetext{
${ }^{3}$ O vídeo está disponível no YouTube e possui duração de 05:56 minutos. O cantor cearense conhecido como Tião Simpatia elaborou um DVD intitulado: Mulher de Lei, no qual se utiliza do cordel para trabalhar a violência contra a mulher. Sobre essa produção ver: Tião Simpatia. A Lei Maria da Penha em Cordel. Texto Tião Simpatia; Ilustrações Meg Banhos. Fortaleza. Armazém da Cultura, 2011.
} 
Dossiê: Ensino de História, História das Mulheres e Desigualdades Sociais no Brasil

Tecnicamente, o gênero pode ser definido como a estrutura de práticas reflexivas do corpo por meio das quais corpos sexuais são posicionados na História.

O curso de Pedagogia é composto majoritariamente por mulheres trabalhadoras, exercendo as funções sociais como mães e avós, que enfrentam diariamente a tripla jornada ao ousarem fazer faculdade no turno noturno.

Muitos são os desafios da/o professora/o do ensino superior, para romper paradigmas e inserir uma análise crítica acerca das narrativas oficiais da produção historiográfica, apontando os apagamentos das mulheres e seus efeitos nefastos para a discussão das desigualdades de gênero na sociedade. Tal como relata Louro elas organizam e ocupam o espaço, elas são as professoras; a atividade escolar é marcada pelo cuidado, pela vigilância e pela educação, tarefas tradicionalmente femininas" (LOURO, 1997, p.88).

Essa oficina permitiu perceber alternativas metodológicas que possibilitem uma inserção didática das mulheres nas propostas pedagógicas, alargando as possibilidades de reconhecimento das violências cantadas por Tião Simpatia. Fundamentalmente, visibilizar as mulheres como protagonistas na história é, inevitavelmente, salientar a historicidade que envolve os discursos de feminilidade e masculinidade.

Ao relatar abusos físicos e psicológicos de maneira lúdica, conseguimos problematizá-los para a construção crítica equitativa que respeite a diversidade de gênero. O cordel viabilizou o lugar de inquietação das discursividades opressoras e violentas, como suporte pedagógico, e essa literatura cantada possibilitou o reconhecimento de violências, da importância da lei e de uma nova postura ante aos abusos, muitos deles desconhecidos ainda pelas formandas em um curso superior, como por exemplo, o da violência patrimonial.

Para Michel Foucault (1996) o discurso, como prática social, só é produzido em razão das relações de poder. É uma tênue premissa de postulados cristalizados, valorando discursos excludentes, tais como etnocentrismo, xenofobia, racismo, sexismo, homofobia, misoginia, dentre tantos outros. O questionamento central discutido nessa oficina, foi a percepção de que a lei não está sendo devidamente trabalhada nos cursos de pedagogia e sequer aparecer como cerne de discussões epistemológicas no campo da Pedagogia para contemplar discussões sobre desigualdades e diferenças de gênero e suas 
Dossiê: Ensino de História, História das Mulheres e Desigualdades Sociais no Brasil

heranças históricas. Essa oficina deixa evidente a necessidade dessa temática ser inserida tanto nos materiais pedagógicos na formação discente dos cursos superiores quanto nos materiais infanto-juvenis a serem trabalhados com as crianças nas escolas. A falta de materiais, discussões e práticas de ensino que promovam saberes que contribuam para a percepção de lutas por direitos, relações sociais e econômicas, e sobretudo os confrontos políticos e sociais, de acordo com Foucault (1996) apoiam-se em cânones de verdades absolutas sobre a sociedade, funcionando como um sistema repressivo, controlador e excludente.

\footnotetext{
Ora, essa vontade de verdade, como os outros sistemas de exclusão, apóia-se sobre um suporte institucional: é ao mesmo tempo reforçada e reconduzida por todo um compacto conjunto de práticas como a pedagogia, é claro, como o sistema de livros, da edição, das bibliotecas, como as sociedades de sábios de outrora, os laboratórios hoje. Mas ela é reconduzida, mais profundamente sem dúvida, pelo modo como o saber é aplicado em uma sociedade, como é valorizado, distribuído, repartido e de certo modo atribuído. (FOUCAULT, 1996, p.17).
}

Os diálogos de gênero no encontro entre a Pedagogia e a História transformam-se em ferramenta de "resistência" ou "reexistência", uma vez que propõem uma concepção educacional capaz de lançar-se a uma ação urgente, percebendo o intolerável, que se corporifica no interstício do pensar, falar e ser. Os relatos da oficina proporcionaram mecanismos de luta subjetiva em prol de uma sociedade equitativa, iniciando o processo de microrrevoluções capazes de ressignificar práticas de opressão. É preciso, portanto, um olhar atento e constante das/dos docentes a respeito da historicidade da constituição das/os sujeitas/os e as subjetividades nele presentes. Com a contribuição analítica da categoria de gênero há um deslocamento de foco de agenciamentos hegemônicos que compõem o campo educacional.

A Lei Maria da Penha produziu subjetividades relacionais, articulando inclusão, exclusão, agenciamento, resistência, manifestados nas diversas relações de poder imbricadas no cordel de Tião Simpatia. Muitos olhos marejados desnudavam empatia e mesmo identificação com uma vida de sofrimento, mas sorrisos tímidos também revelavam a resistência depositada no 
Dossiê: Ensino de História, História das Mulheres e Desigualdades Sociais no Brasil

ato de estudar, de se formar e até mesmo de estarem vinculados ao período noturno.

Aliás, o estudo noturno constitui por si, uma forma de resistência e desafio aos sistemas de poderes e das desigualdades sociais que mantém e reproduzem os empregos subalternos e as diferenças salariais entre os que possuem ensino superior e os que não possuem. Os pedidos constantes para sair mais cedo, tanto demonstram as marcas de classe quanto demarcavam espaços de vulnerabilidade de gênero: a violência sexual, invisível e ao mesmo tempo tangível, que ronda o ponto de ônibus na periferia à noite.

Oficina 2: Leodegária de Jesus e a poesia visual

A poesia foi outra importante ferramenta discursiva utilizada na oficina. Como proposta de leitura e pesquisa, fomentamos a importância da escrita de mulheres e o cerne de reflexão dessa oficina, pautou-se na problematização da vida e obras de Leodegária de Jesus, como poetisa e mulher negra de Goiás. Historicamente, o lugar de fala da poeta atravessa a reflexão da ação política e cultural de mulheres negras de grupos subalternizados, frente aos modos de subjetivação marcados pelo racismo e sexismo.

A necessidade de se pensar outros saberes e desestabilizar a epistemologia dominante, implica em encontrar lugares de fala, partindo da premissa de ser pensada a partir de si. A partir da poesia de Leodegária, ao final do encontro, cada discente apresentou de forma livre uma poesia visual ${ }^{4}$ que expressasse parte da leitura de si e do outro. A escolha didática da poesia visual como culminância da oficina, parte da intersecção entre a poesia e a experimentação visual, com possibilidades distintas de expressar o não dito. Buscou-se na proposta metodológica da oficina explicitar a interseccionalidade

\footnotetext{
${ }^{4} \mathrm{~A}$ poesia visual busca trabalhar as características plásticas da escrita ressaltando os valores visuais, espaciais. De acordo com Menezes (1998), importante ensaísta e pesquisador desse tema: "Por "poesia visual" pode-se entender toda espécie de poesia ou texto que utilize elementos gráficos para se somar às palavras, em qualquer época da história e em qualquer lugar; já "poesia concreta" é um estilo de poesia visual que nasce num dado período histórico, com características bem definidas. [...] O termo "poesia experimental", assim, é o nome que se dá a toda e qualquer forma de poesia moderna que utiliza recursos fora do texto versificado tradicional, aquele tipo de escrita que se ligava a um mundo em desaparecimento ou, ao menos, em transformação" (MENEZES, 1998, p. 14-15).
} 
Dossiê: Ensino de História, História das Mulheres e Desigualdades Sociais no Brasil

de gênero e raça, como ferramenta analítica, dialogando contra as diversas violências que atravessam as histórias das mulheres.

Mulher negra, a poeta Leodegária de Jesus deixou um legado de saberes que expõe a dificuldade das mulheres dos séculos XIX e XX no interior de Goiás, marcado por uma cultura escravocrata e aristocrática, que subvalorizava a mulher, principalmente as mulheres negras. O infográfico produzido pelos discentes buscou mostrar a importância dessa mulher negra na História da Literatura e ressaltar a importância de sua contribuição histórica.

A reflexão mais significativa da oficina foi a importância e o silenciamento a respeito de uma poeta de tamanho vulto como Leodegária de Jesus: mulher negra, da Província de Goyaz, em princípios da República no Brasil ${ }^{5}$. As integrantes da produção do infográfico salientavam, com veemência, que a poeta foi pioneira ao publicar um livro de poesia, em 1906, além de integrar a comunidade intelectual feminina. Houve também um grande destaque ao fato de Cora Coralina ser sua amiga pessoal.

A imagem da mulher branca e intelectual disputava com a informação de uma mulher negra ocupar um lugar de fala na Oficina. Inicialmente houve certa estranheza com o lugar de fala da mulher negra, que logo tomou a forma de admiração e surpresa. Durante a oficina, pensada como uma experiência prática e teórica, o racismo estrutural arraigado e sedimentado por saberes históricos apareceu com toda a sua potência para, justamente, ser problematizado e debatido. Aquele momento foi uma quebra de paradigmas para começar a trazer à tona as inúmeras situações nas quais as mulheres negras foram, historicamente, confinadas a um não-lugar ou ao espaço da subalternidade.

De acordo com Tânia Ferreira Rezende

Leodegária de Jesus ocupa um lugar na sociedade vilaboense, o lugar de mulher, um lugar que ela conquistou. Mas seu corpo define a ocupação desse lugar. Ela é uma mulher negra, filha de negro, professor, que vem de baixo. [...] Sua importância para a

\footnotetext{
${ }^{5}$ Sobre a contextualização histórica da poetisa Leodegária de Jesus, a possibilidade de integrar a classe da intelectualidade de Vila Boa e seu contato com a elite branca, a autora Tânia Ferreira Rezende faz uma ampla abordagem sobre o assunto. REZENDE, Tânia Ferreira. A semiótica dos corpos na literatura goiana: o corpo negro de Leodegária de Jesus. Revista Plurais - Virtual, v. $8, \quad$ n. 1 , p. 131-159, jan./abr. 2018. Disponível em: https:// www.revista.ueg.br/index.php/revistapluraisvirtual/article/view/9177 acesso em 01 de Junho de 2020.
} 
Dossiê: Ensino de História, História das Mulheres e Desigualdades Sociais no Brasil

literatura goiana, por ser a primeira mulher a publicar livros de poemas, não é reconhecida, por muito tempo. (REZENDE, 2018b, p. 149).

Refletimos sobre algumas questões cruciais: a vida e a obra de Leodegária foram marcadas pelo seu corpo negro; a invisibilidade de sua obra é marcada pela ferida racial de uma sociedade racista e patriarcal, que prefere dar voz a uma mulher branca como Cora Coralina, a despeito das relações afetivas entre as duas.

Esta primeira reflexão gerou um outro debate central: a percepção das marcas de gênero nos corpos, traçadas pelas narrativas e pelos saberes da Educação. Diversas mulheres negras que participaram da oficina manifestaram suas próprias experiências pessoais de constrangimento, assédios e racismos e, inclusive, o discente homem homossexual pode refletir e expressar suas angústias e sofrimentos, por ter ele mesmo um corpo marcado como alvo de ataque da estrutura patriarcal branca heteronormativa. Dores, silenciamentos e feridas marcadas pelo racismo e pelo sexismo.

É importante ressaltar que resgatar a importância da obra de Leodegária de Jesus representa uma ruptura com o padrão da branquitude produtora de saberes e falas intelectuais como uma ação política fundamental para a demonstração de uma História múltipla e uma Educação para a Diversidade. A partir dos versos de Leodegária, as/os discentes participantes debateram temas centrais para uma educação equitativa, diversa e plural: os desafios das classes mais baixas em cursar o ensino superior; lugares de fala; relações de poder cotidianas e racismo. Foi uma oficina intensa e plena de questionamentos, angústias e um processo gradual de quebras de silenciamentos. As discentes mulheres, mães, avós, donas de casa, trabalhadoras - tomaram para si o protagonismo do debate e lideraram a discussão: protagonistas de suas próprias ações, ao verem uma outra mulher negra que ousou falar de si, agora sentiam poder e sentido em suas próprias palavras, sentimentos e reivindicações. Leodegária mostrou a elas, a força da visibilidade e a importância de serem ouvidas e valorizadas. De acordo com Sueli Carneiro

Quando falamos em romper com o mito da rainha do lar, da musa idolatrada dos poetas, de que mulheres estamos falando? As mulheres negras fazem parte de um contingente de mulheres 
Dossiê: Ensino de História, História das Mulheres e Desigualdades Sociais no Brasil

que não são rainhas de nada, que são retratadas como antimusas da sociedade brasileira, porque o modelo estético de mulher é a mulher branca. (CARNEIRO, 2019, p.314).

Na culminância da Oficina Leodegária de Jesus e Poesia Visual, partiu-se para a prática: a proposta metodológica cunhava-se na perspectiva de que todas/os tinham lugar de fala por meio da poesia para o fechamento da oficina. Uma enorme projeção de mural fixou todas as poesias visuais e cada discente expressou sua maneira de entender a si e o mundo à sua volta.

Bourdieu (1988) afirma que a sociedade foi constituída dentro de um projeto de poder na qual vigora a "dominação masculina": as mulheres preservam e são as guardiãs da "sacralidade maternal" como responsáveis exclusivas pela harmonia no lar enquanto os homens são os responsáveis por tudo que é considerado importante socialmente.

\begin{abstract}
A dominação masculina, que constitui as mulheres como objetos simbólicos, cujo ser (esse) é um ser-percebido (percipi), tem por efeito colocá-las em permanente estado de insegurança corporal, ou melhor, de dependência simbólica: elas existem primeiro pelo, e para, o olhar dos outros, ou seja, enquanto objetos receptivos, atraentes, disponíveis. Delas se espera que sejam "femininas", isto é, sorridentes, simpáticas, atenciosas, submissas, discretas, contidas ou até mesmo apagadas. E a pretensa "feminilidade" muitas vezes não é mais que uma forma de aquiescência em relação às expectativas masculinas, reais ou supostas, principalmente em termos de engrandecimento do ego. Em consequência, a dependência em relação aos outros (e não só aos homens) tende a se tornar constitutiva de seu ser. (BOURDIEU, 1998, p. 82).
\end{abstract}

Nas poesias selecionadas da fotografia 1, podemos perceber essa estrutura denunciada por Bourdieu, com base em alguns elementos simbólicos no campo subjetivo. A sacralidade maternal é explicitada na imagem em que a mãe é o elo com suas/seus filhas/os, onde todo movimento é em virtude da maternidade: o que pressupõe que toda a vida das mulheres está diretamente ligada ao fator da maternidade. Interessante salientar que a figura do pai das crianças não é mencionada no movimento de vida daquela família.

A outra imagem que merece destaque é a representação focal da aliança, demonstrando a importância do matrimônio. Na mão desenhada é notório o papel central que a discente enfatiza em torno do casamento. A percepção de si 


\section{HISTÓRIA}

Dossiê: Ensino de História, História das Mulheres e Desigualdades Sociais no Brasil como proposta da atividade, se deu em detrimento da sua percepção do outro. A constituição dessa imagem está intimamente ligada ao matrimônio simbolizado pela aliança.

Como é possível observar na fotografia 1, o lugar das mães está ligado à família e ao casamento: todo os cuidados com os/as filhas/filhos cabem a elas, e os papéis designados às mulheres estão intrinsecamente ligados aos parâmetros familiares e estado civil.

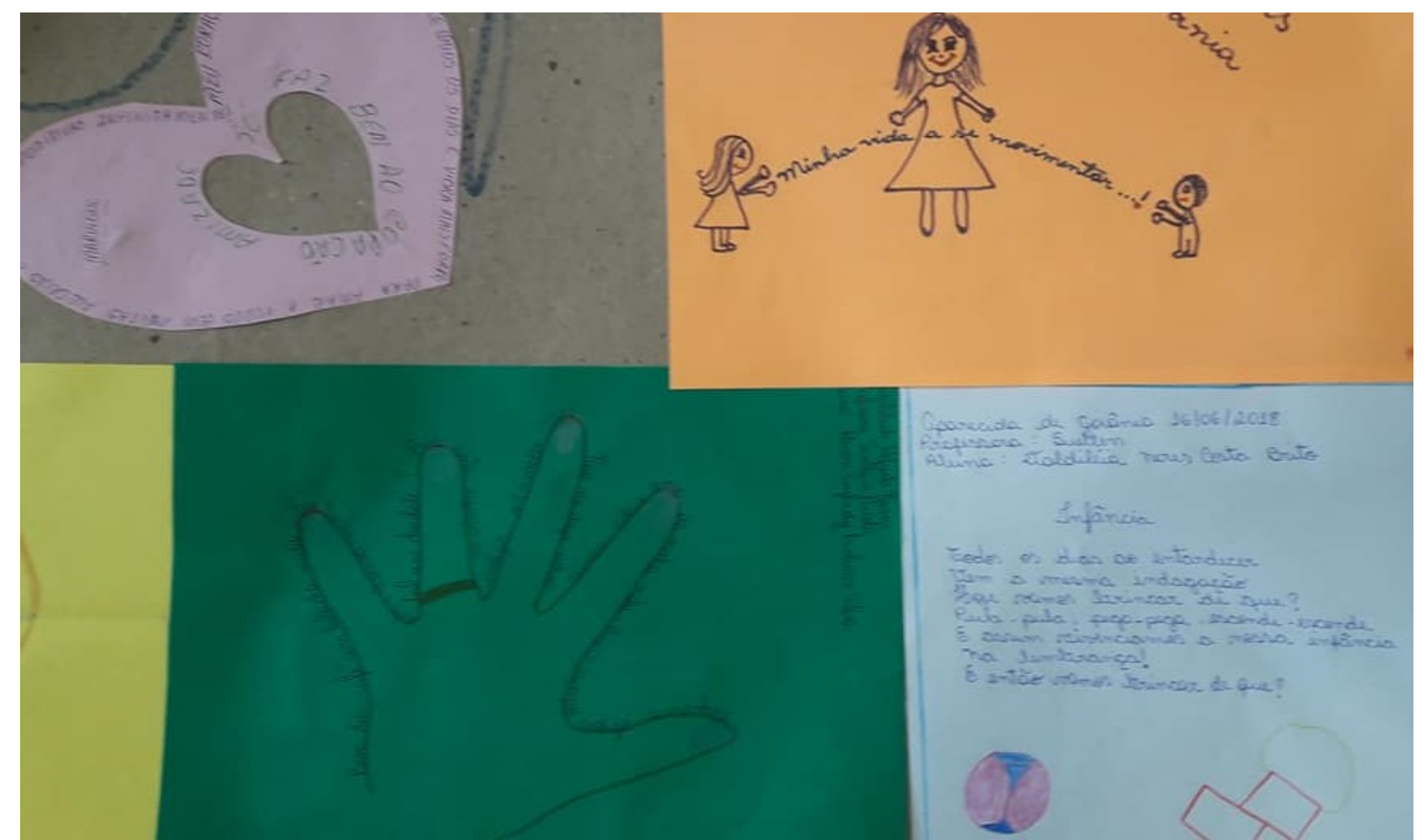

Fotografia 1- Oficina de poesia visual. Acervo pessoal.

A fotografia 2 remete a outro aspecto interessante: um barco à deriva no mar, um sol sorrindo e dizeres que se referem à oportunidade de pensar, a discente faz a relação da bandeira com a docente, que a levou (o barco pequeno) a ser orientada a pensar, no mar que pode ser associado a imensas oportunidades que o mundo acadêmico lhe proporcionou. Neste aspecto, a educação funciona como um agente transformador das sujeitas, tornando-as protagonistas de suas navegações e de subjetividades marcadas pelos questionamentos sobre a necessidade de uma sociedade com maior equidade de gênero.

A diferentes saberes mobilizados nessas oficinas, deixaram como legado uma importante lição: as/os discentes sempre são protagonistas de seus conhecimentos. Elas/eles mobilizam os saberes, e mesmo aquilo que parece 


\section{HISTÓRIA}

Dossiê: Ensino de História, História das Mulheres e Desigualdades Sociais no Brasil

cristalizado e passivo, pode vir a se descortinar em posicionamentos corajosos de compartilhamento de dor, superação e alegrias de viver.

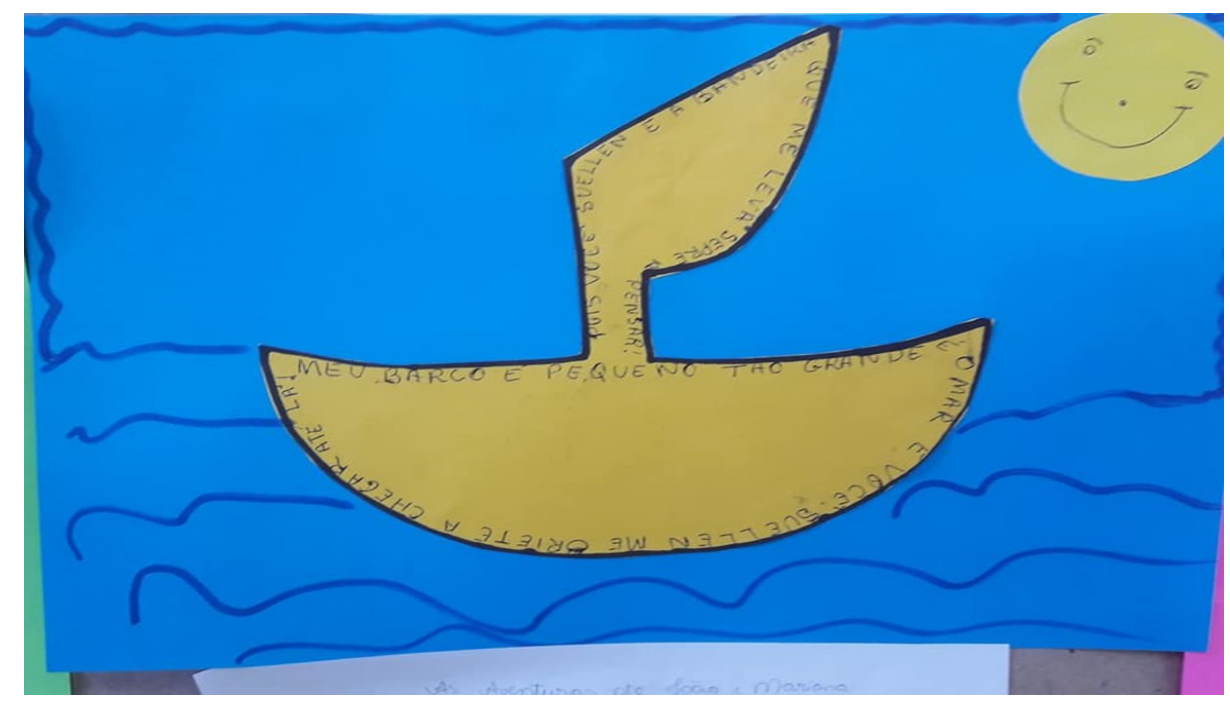

Fotografia 2. Oficina de Poesia Visual. Acervo Pessoal.

$\mathrm{Na}$ expressão da poesia visual da fotografia 2, destacamos o interesse da discente ao espaço para a discussão dos estudos de gênero e sexualidades. As disciplinas práticas foram mencionadas por essa acadêmica como um caminho possível para se tratar tais temas transversais. No entanto, é crucial questionar como o curso de Pedagogia têm nos últimos anos oferecido subsídios necessários para ampliar as discussões em torno da análise de Gênero.

Os processos experienciais provaram que na organização das três oficinas inovadoras, como projetos curriculares, existiu uma preocupação em se discutir acerca da formação do profissional de pedagogia, inserindo temáticas plurais sobre diversidade, História e relações de gênero.

Marília Pinto Carvalho (2010) nos elucida acerca da diferença marcante no campo da Pedagogia marcado pela presença feminina e de um certo sexismo à entrada dos homens nesse ofício atualmente. O ofício das "pedagogas" está ligado ao cuidado e à doação, sempre. Quanto aos homens, em sua grande maioria, seguem a carreira acadêmica no ensino superior, voltando-se para atividades intelectuais teóricas ou se tornam gestores nas escolas. De acordo com a autora:

Os professores homens elegem como última opção o magistério: As principais conclusões de estudos recentes vão na direção de que os homens optam tardiamente pela carreira de magistério, 
Dossiê: Ensino de História, História das Mulheres e Desigualdades Sociais no Brasil

muitas vezes tendo percorrido outras opções profissionais; tendem a sofrer maiores pressões tanto em direção a outras ocupações, quanto no sentido da ascensão na carreira, quase sempre para deixar a sala de aula e ocupar cargos administrativos; e em geral fazem planos para o futuro mais amplos que as mulheres, envolvendo mais frequentemente atividades fora de sala de aula ( CARVALHO, 2010, p.07).

Oficina 3: Educação Holística: Gênero, Educação e Diversidade

A última Oficina da Semana Pedagógica se configurou com a apresentação de slides e debate sobre Educação Holística6: Gênero, Educação e Diversidade. A visão do holismo na ciência traduz-se pela crença na existência de uma alma, imbuída pela vontade do ser, que se conecta ao universo. A relação do holismo com a ciência e a educação, corresponde ao envolvimento de todos num processo educacional, estimulando-se os sentimentos de compaixão e esperança envolvendo intelecto, emoções e força física.

A educação holística propicia uma nova visão do ser relacionado ao mundo. Integrando o ser no seu próprio sentido de ser, partindo do autoconhecimento. Desse modo, os estudos de gênero e diversidade coadunam com a educação para o século XXI, desenvolvendo empatia e solidariedade norteados por preceitos democráticos.

A Visão Holística da Educação é um novo modo de relação do ser humano com o mundo; uma nova visão do outro e de si mesmo, e partindo da premissa de uma educação transformadora, oficina foi conduzida segundo o Relatório da Comissão Internacional de Educação para a UNESCO, intitulado "Educação: um tesouro a descobrir ${ }^{7}$ ", que é a base para documentos e pareceres do MEC, encontrados nos $\mathrm{PCN}^{8}{ }^{8}$, e no $\mathrm{PNE}^{9}$, com quatro pilares básicos da Educação

\footnotetext{
${ }^{6}$ Sobre o assunto Cf. CREMA, Roberto. Visão Holísitica em Psicologia e Educação. São Paulo SP: Summus, 1991.

7 Sobre o assunto: Cf. DELORS, Jacques. Educação: um tesouro a descobrir. 8. Ed. São Paulo: Cortez; Brasília, DF: MEC: UNESCO, 2003.

${ }^{8}$ Em diálogo com a Educação Holística, é importante situar a relação com os estudos de gênero. A discussão sobre gênero e sexualidade foi proporcionada por meioE do tema transversal Orientação Sexual v.10, considerando a importância sobre diversos aspectos da relação de gênero e sexualidade (PCN, 2001, v.10).

9 Dialogando com os princípios da Educação para o Século XXI, relacionamos gênero às normativas de resolução do CNE/CP N ${ }^{\circ}$ 2, de 22 de Dezembro de 2017. O Conselho Nacional de Educação, em seu capítulo III da Base Nacional Curricular, estabeleceu a retirada dos termos "gênero" e "orientação sexual" de trechos específicos que constavam no artigo de número 16.
} 
Dossiê: Ensino de História, História das Mulheres e Desigualdades Sociais no Brasil

para os dias atuais: aprender a fazer; conhecer; ser; viver juntas/os, e para tal, entendemos o tema como fundamental e crucial ante os desafios da Educação do século XXI.

Dialogar com o conceito analítico de gênero, corrobora com todas as facetas mencionadas por Rafael Yus, em sua obra Educação Integral: uma educação holística para o século XXI. São consideradas todas as facetas da experiência humana, não só o intelecto racional e as responsabilidades de vocação e cidadania, mas também os aspectos físicos, emocionais, sociais, estéticos, criativos, intuitivos e espirituais inatos da natureza do ser humano". (YUS, 2002, p.16).

No último dia, com uma exposição dialogada, alguns pontos cruciais foram inseridos: as facetas dialógicas sobre as relações de gênero e diversidade, uma vez que o propósito da última oficina foi tentar pensar em uma nova leitura de mundo possível mais justo e equitativo. Nesse sentido, a História conecta-se se com a pedagogia em uma proposta para educação no século XXI ligada à transformação e formação efetiva de sujeitas/os críticas/os e ativas/os na sociedade.

No que tange a interdisciplinaridade é de suma importância assumir debates que incorporem a perspectiva equitativa, e é com base nos estudos de gênero que podemos romper paradigmas tradicionais e desiguais, que ainda permeiam a nossa sociedade: voltados às intolerâncias, preconceitos, racismos e sexismos. A interlocução com as reflexões analíticas de gênero assumiu o papel educativo para que as/os futuras/os educadoras/es pudessem se tornar agentes de transformações sociais através de suas atividades docentes. Garantir direitos e questionar os silenciamentos intrínsecos na História, corrobora para que a Educação seja um terreno fértil de múltiplos ensinos e espaços, propondo caminhos viáveis para um pensamento analítico (REZENDE, 2018a).

A partir da proposta de trazer à luz as questões de Gênero e Diversidade na Escola, as discussões permearam a certeza de que não bastam leis, se não houver a transformação de mentalidades e práticas. Muitos foram os

No que se refere ao novo PNE, que contempla os anos de 2011 a 2020 , e metas a serem alcançadas, a substituição ficou a cargo de superação das desigualdades educacionais, com ênfase nas questões de igualdade racial, regional e princípios de equidade e respeito. Disponível em: (BRASIL, CNE, 2017. p.05). 
Dossiê: Ensino de História, História das Mulheres e Desigualdades Sociais no Brasil

questionamentos: as mulheres ligadas às religiões cristãs neopentecostais, apresentaram bastante relutância em reconhecer a as lutas feministas e os estudos de gênero, muito embora também se reconhecido dentro do processo de discussão, ao se perceberem assumindo uma sobrecarga de trabalhos domésticos e ao reconheceram a oposição dos companheiros/maridos em fazer faculdade à noite e saírem de casa. Ou seja, talvez caiba uma investigação mais profunda de como as "lutas feministas" tem sido explicadas em suas redes de sociabilidades religiosas. Ao se sentirem parte das reclamantes, ainda assim essas mulheres relutavam em se dizerem "feministas".

As ações que promoveram a discussão desses temas motivaram a reflexão individual e coletiva e contribuíram para a tentativa de superação e eliminação dos tratamentos preconceituosos na educação. Diante dos postulados de que a Pedagogia assume "pretensas verdades" em relação à feminilização do magistério, desconsiderando a historicidade dessa profissão, IIma Veiga (1997) problematiza as bases esses discursos de "verdade"

Certamente seria reducionismo conceitual considerar a questão da feminização do magistério como algo dado, ou seja, como um fenômeno natural. Ao contrário, é preciso redimensioná-la, discutindo a relação mulher-educação como produto da teia de relações sociais em que, entre outros aspectos, se contempla o binômio desse gênero. Nesse sentido, é bastante pertinente a denúncia de que grande parte da pesquisa educacional deixa de incorporar a questão do sexo da professora como um elemento associado às relações de trabalho predominantes na sociedade (VEIGA, 1997, p.28).

Diante de tal problemática, a intervenção pautada nas noções das transformações coletivas, elencaram algumas questões: se a educação holística e a intersecção com gênero nos faz refletir sobre tais assimetrias, como seremos capazes de transformarmo-nos em educadoras/es ativas/os e autodeterminadas/os em busca de autonomia para a reconstrução do mundo? Como poderemos ter sensibilidade e criatividade para a criamos formas de lutas e resistência? Como poderemos ser solidárias/os opondo-nos ao acúmulo de poder nas mãos de tão poucas pessoas e buscando, portanto, maior equidade social? Como podemos ser autoconscientes em busca do bem-estar, paz e amor 
Dossiê: Ensino de História, História das Mulheres e Desigualdades Sociais no Brasil

estimulando o "compartilhar" de saberes? Todos os questionamentos perpassam por discussões dos estudos de gênero e da História.

Enfim, a perspectiva de (re)construção de um mundo mais equitativo proposta pela Pedagogia holística perpassa o próprio repensar da ideia de currículo, uma vez que é preciso confrontar novos posicionamentos no que concerne à Educação, incluindo as discussões sobre relações de gênero e sexualidades, até então renegadas à margem como um assunto polêmico e problemático.

Acerca da aversão no que ser refere à pluralidade e ao desconhecimento de alguns termos como diversidade, Louro nos confronta com os processos que produzem diferença dentro da Pedagogia.

\begin{abstract}
Uma pedagogia e um currículo queer se distinguiriam de programas multiculturais bem intencionados, onde as diferenças (de gênero, sexuais ou étnicas) são toleradas ou são apreciadas como curiosidades exóticas. Uma pedagogia e um currículo queer estariam voltados para o processo de produção das diferenças e trabalhariam, centralmente, com a instabilidade e a precariedade de todas as identidades. Ao colocar em discussão as formas como o "outro" é constituído, levariam a questionar as estreitas relações do eu com o outro. A diferença deixaria de estar lá fora, do outro lado, alheia ao sujeito, e seria compreendida como indispensável para a existência do próprio sujeito: ela estaria dentro, integrando e constituindo o eu. A diferença deixaria de estar ausente para estar presente: fazendo sentido, assombrando e desestabilizando o sujeito. Ao se dirigir para os processos que produzem as diferenças, o currículo passaria a exigir que se prestasse atenção ao jogo político aí implicado: em vez de meramente contemplar uma sociedade plural, seria imprescindível dar-se conta das disputas, dos conflitos e das negociações constitutivos das posições que os sujeitos ocupam ( LOURO, 2001. p.550).
\end{abstract}

No debate, todas/os foram unânimes no reconhecimento de que, em meio às notáveis desigualdades de gênero estruturadas por um sistema patriarcal e excludente, fomentam-se contínuas violências (física, psicológica, sexual e econômica). Durante a discussão, tornou-se evidente que a escola tem papel fundamental na formação e modificação de tais segregações. Assim, o trabalho da oficina na formação de futuras/os professoras/es foi pontual na desconstrução de modelos educacionais opressores. Algumas considerações reflexivas: não obtivemos consenso no que tange às noções sobre as liberdades sexuais; no que diz respeito à interferência religiosa na educação e na inserção 
Dossiê: Ensino de História, História das Mulheres e Desigualdades Sociais no Brasil do profissional homem (cis ou trans) de pedagogia quanto aos cuidados com as crianças. Contudo, a proposta de construir um espaço plural de discussões e respeito, visando, não só a igualdade, mas sobretudo, a equidade das relações de gênero, avalia-se de maneira exitosa, uma vez que diversas temáticas puderam ser questionadas e contextualizadas historicamente como práticas sociais construídas e não naturalizadas.

Entendemos que a categoria analítica de gênero surge no espaço de reflexão e debate da Faculdade de Educação, como um instrumento político de questionar e debater os silenciamentos de sujeitas/os históricas/os, no campo da Pedagogia. A ebulição de concepções e problematizações discutidas no Projeto de Leitura, demonstrou a vivacidade desses debates nos cursos de formação e demarcou o interesse no aprofundamento a respeito de muitas lutas e demandas colocadas em pauta em todas as Oficinas, tais como: preconceitos, liberdades, lugares de fala, violências, sexualidades, orientações sexuais, ética. Buscamos desnaturalizar e historicizar as diferenças, colaborando no processo de construção crítica e no desenvolvimento de uma nova forma de análise histórica. De suma importância é salientar a possibilidade de se tratar os temas gênero e sexualidade na Educação como um todo.

Na finalização do momento reflexivo, uma discente questionou: "afinal, a educação de mulheres e homens, meninas e meninos deve ou não ser diferente?"

Presumimos que, ao que parece, as questões que norteiam essas discussões ainda precisam ser muito refletidas. O poder não é, pois, uma instituição nem uma estrutura e, também, não é uma certa potência de que alguns sejam dotados, mas uma situação estratégica complexa numa sociedade determinada (FOUCAULT, 1996). Como também reforça Guacira Lopes Louro,

Os processos escolares como formadores e reprodutores de desigualdades sociais vêm ocupando a agenda política e acadêmica de muitos/as estudiosos e estudiosas críticos/as há várias décadas (LOURO, 1997, p. 110).

Outro ponto de discussão intensa foi relacionado a brincadeiras. As brincadeiras são pré-determinadas por conta do gênero, e na escola a liberdade das brincadeiras é limitada. Relacionamos esse fato, à enorme dificuldade de 
Dossiê: Ensino de História, História das Mulheres e Desigualdades Sociais no Brasil

divisão de tarefas domésticas e aos cuidados com os filhos, funções essas atribuídas ao papel social historicamente vinculado às mulheres.

Os lugares de brincadeiras deveriam ser ocupados de forma mais igualitária, sem concentração de meninos em uma parte e meninas em outra. Nesse sentido, outro debate se impôs na oficina: o de meninos brincarem com bonecas como um grande problema e isso ser um vínculo direto à orientação sexual da criança estar diretamente ligada ao brinquedo em questão.

A partir dessa observação, foram feitos alguns questionamentos a respeito da importância da intervenção dos adultos para o direcionamento de brincadeiras e brinquedo. E nesse contexto, foi possível mapear as diferenças, os preconceitos na organização pedagógica, na formação de currículos e na ambiência da escola como extensão direta dos lares.

Diferenças, distinções, desigualdades... A escola entende disso. $\mathrm{Na}$ verdade, a escola produz isso. [...]. Ela dividiu também, internamente, os que lá estavam, através de múltiplos mecanismos de classificação, ordenamento, hierarquização. A escola que nos foi legada pela sociedade ocidental moderna começou por separar adultos de crianças, católicos de protestantes. Ela também se fez diferente para os ricos e para os pobres e ela imediatamente separou os meninos das meninas. (...) Os novos grupos foram trazendo transformações à instituição. Ela precisou ser diversa: organização, currículos, prédios, docentes, regulamentos, avaliações iriam, explícita ou implicitamente, "garantir" — e também produzir — as diferenças entre os sujeitos (LOURO,1997, p.57).

O próximo passo na discussão foi elencar alguns personagens animados e, dentre os mais comentados, surgiu a personagem Moana. A respeito dela foram enaltecidas as ideias de que ela auxilia na desconstrução de estereótipos sobre as meninas e revela características importantes e pouco valorizadas na educação delas: autenticidade, persistência, coragem e subversão aos limites impostos (uma certa teimosia refratária às normas). Todas essas características foram mencionadas de maneira positiva como uma quebra de paradigmas tradicionais do conceito de feminilidade pensado socialmente, conforme Soares (2015), como características "inerentes e essenciais" das mulheres, mas que são, como todos os conceitos que permeiam os estudos de gênero, parte de uma 
Dossiê: Ensino de História, História das Mulheres e Desigualdades Sociais no Brasil construção histórica cultural e social que serve a determinadas agendas políticas de estabelecimento de papéis e condutas sociais.

A discussão das narrativas tradicionais das histórias animadas voltadas para as meninas, em que havia sempre uma princesa vestida de rosa à espera do príncipe, é rompida uma vez que Moana se apresenta uma jovem independente, corajosa e sem príncipe encantado. (PARKER,1991). Em outras palavras, Moana representa uma nova possibilidade de feminilidade, dentro de outros parâmetros e outras formas de viver e agir no mundo. Moana é forte, valente, capaz de enfrentar deuses e mares bravios e ao mesmo tempo, se veste com uma saia típica de sua cultura e carrega uma flor nos cabelos.

A grande maioria das mulheres na discussão da Oficina reiterou a importância de se criar novos signos na construção cultural das brincadeiras. Para Auad (2006, p. 21): [...] gênero não é sinônimo de sexo (masculino e feminino). As relações de gênero correspondem ao conjunto de representações construído em cada sociedade, ao longo de sua história, para a atribuição de significados, símbolos e diferenças. Embasada nessas diferenças e significados, a construção de símbolos deve ser alicerçada, a fim de que tenhamos relações sociais democráticas. Moana claramente representa um exemplo pontual, imbricada à ideia de construção social e histórica de princesas, explicitando que o imaginário infantil pode ser construído de forma equitativa. Moana revela a ausência de príncipe, a coragem e um novo paradigma: a emancipação das mulheres.

Como maior legado da experiência com a prática de oficinas na Semana Pedagógica do Projeto de Leitura no ano de 2018 foi o aprendizado de que a práxis humana transcende a teoria quando há necessidade. Mulheres e homens no curso de Pedagogia resistiam e re(existiam) a cada obstáculo de desnaturalização, desvelando a imensa dificuldade da Educação no Brasil. Necessitamos com urgência rediscutir as relações entre produção científica e práxis educacional.

Os sentidos que orientam os professores as construções dos professores nas salas de aula, por sua vez, interferem e contribuem para a leitura de mundo e configuração de realidades. Sem negar a existência de uma realidade, o conhecimento histórico permite compreendê-lo de diferentes formas, reconhecendo a possibilidade da mudança, a superação de sua circunstância, a negação de poderes constituídos. "Dizer 


\section{HISTÓRIA}

Dossiê: Ensino de História, História das Mulheres e Desigualdades Sociais no Brasil uma palavra é transformar o mundo..." (MONTEIRO, 2007, p. 235)

Discutir Educação e História através do olhar analítico dos estudos de gênero é partir para um caminho de emancipação e cidadania. É ampliar a atuação das/os profissionais de Pedagogia a múltiplos espaços como sujeitas/os históricas/os. Protagonizar a própria existência implica em um olhar altruísta na produção de discursividades, exercendo um lugar de fala que constrói um contexto dialógico.

Gênero, como nosso objeto de estudo, é, de fato, as respostas (contingentes, contenciosas e mutáveis) oferecidas para a irrespondível questão. De fato, as regulações normativas que estabelecem os papéis de gênero são tentativas de tornar a questão impossível de ser questionada. Como resultado, gênero é um lugar perpétuo para a contestação política, um dos locais para a implantação do conhecimento pelos interesses do poder." (SCOTT, 2012, p. 346)

Aliar os estudos de gênero, educação e história é um caminho possível e muito promissor, para as/os docentes pensarem em suas ações em sala de aula. Essas áreas unidas funcionam como propulsores de emancipação estabelecendo dialogicidades entre as relações de gênero como análise histórica e a Pedagogia - basilares para as discussões teórico-pedagógicas da formação docente. Os estudos de gênero na experiência didática das oficinas temáticas foram um eixo agregador eficaz e uma ferramenta analítica fundamental para os debates, no sentido da construção de uma ideia de educação equitativa e holística, contemplando as/os sujeitas/os e descortinando e contextualizando historicamente as imposições sexistas e assimetrias sociais.

\section{Referências}

AUAD, Daniela. Feminismo: que história é essa? Rio de Janeiro: DP\&A, 2003.

AUAD, Daniela. Educar Meninos e Meninas: Relações de Gênero na Escola. São Paulo: Contexto, 2006. 


\section{HISTÓRIA}

Dossiê: Ensino de História, História das Mulheres e Desigualdades Sociais no Brasil

BOURDIEU, Pierre. A dominação masculina. Rio de Janeiro: Bertrand Brasil, 2002.

BOURDIEU, Pierre. Escritos de Educação. Petrópolis: Vozes, 1998.

BRITZMAN, Deborah. Curiosidade, sexualidade e Currículo. In: LOURO, Guacira Lopes (ORG.) O corpo educado: pedagogias da sexualidade. $2^{\mathrm{a}}$ ed. Belo Horizonte: Autêntica, 2001.

CABRINI, Conceição; CIAMPI, Helenice; VIEIRA, M. do Pilar; PEIXOTO, M. do Rosário; BORGES, Vavy Pacheco. $O$ ensino de História: revisão urgente. São Paulo: Brasiliense, 1994.

CARNEIRO, Sueli. Enegrecer o feminismo: a situação da mulher negra na América Latina a partir de uma perspectiva de gênero. Hollanda, Heloisa Buarque(Org.). Pensamento Feminista -conceitos fundamentais. Rio de Janeiro: Bazar do Tempo, 2019, p. 313-321.

CARVALHO, Marília Pinto. Gênero na sala de aula: a questão do desempenho escolar. In: CANDAU, Vera Maria., MOREIRA, Antônio Flávio.

Multiculturalismo. $4^{\mathrm{a} e d}$. Rio de Janeiro: Vozes, 2010.

CARVALHO, Marília Pinto. Vozes Masculinas Numa Profissão Feminina: o que têm a dizer os professores/as? 1998. Disponível em:

http://lasa.international.pitt.edu/LASA98/PintodeCarvalho.pdf. Acesso em 20 de Maio de 2020.

CONNEL, Raewyn. Gênero em termos reais. São Paulo: Nverso, 2016.

CREMA, Roberto. Visão Holísitica em Psicologia e Educação. São Paulo SP: Summus, 1991.

DELORS, Jacques. Educação: um tesouro a descobrir. 8. Ed. São Paulo: Cortez; Brasília, DF: MEC: UNESCO, 2003.

FOUCAULT, Michel. A ordem do discurso. São Paulo: Ed. Loyola, 1996.

LOURO, Guacira Lopes. Um Corpo Estranho - Ensaios sobre sexualidade e teoria queer. Belo Horizonte: Autêntica, 2004.

LOURO, Guacira Lopes. Gênero, sexualidade e educação: uma perspectiva pós-estruturalista. Petrópolis: Vozes, 1997.

LOURO, Guacira Lopes. Pedagogias da sexualidade. In LOURO, Guacira Lopes (ORG.) 0 corpo educado: pedagogias da sexualidade. $2^{a}$ ed. Belo Horizonte: Autêntica, 2001. 


\section{HISTÓRIA}

Dossiê: Ensino de História, História das Mulheres e Desigualdades Sociais no Brasil

MENDES, Simone. Entre o factual e o ficcional: a construção

(pré)discursiva do ethos em um cordel de acontecimento. Entrepalavras, Fortaleza, ano 2, v. 2, n. esp., p. 83-97, jan./jul. 2012.

MENEZES, Philadelpho. Roteiro de leitura: poesia concreta e visual. São Paulo: Editora Ática, 1998.

MONTEIRO, Ana Maria F. C. Professores de História: entre saberes e práticas. Rio de Janeiro: Mauad, 2007.

PARKER, Richard G. Corpos, prazeres e paixões: a cultura sexual no Brasil contemporâneo. São Paulo: Best-Seller/Abril Cultural, 1991.

PAVIANI, Neires Maria Soldatelli \& FONTANA, Niura Maria. Oficinas

pedagógicas: relato de uma experiência. In: Conjectura, Caxias do Sul, V.14, n², p.77-88, maio/ago. 2009.

PERROT, Michelle. Minha história das mulheres. São Paulo: Contexto, 2007.

REZENDE, Suellen Peixoto de. Mulheres nos livros didáticos de história:

Discurso androcêntrico em salas de aulas goianas entre 2008-2013.

Dissertação de mestrado defendida no PPGH/UFG. 2018a.

https://repositorio.bc.ufg.br/tede/handle/tede/9320 Acesso em 20 de Maio de 2020

REZENDE, Tânia Ferreira. A semiótica dos corpos na literatura goiana: o corpo negro de Leodegária de Jesus. Revista Plurais - Virtual, v. 8, n. 1, p. 131-159, jan./abr. 2018b. https://

www.revista.ueg.br/index.php/revistapluraisvirtual/article/view/9177 Acesso em 20 de Maio de 2020

SCOTT, Joan W. Gênero: uma categoria útil de análise histórica. Educação e Realidade, vol. 16, no 2, Porto Alegre, jul./dez. 1990.

SCOTT, Joan W. Os usos e abusos do gênero. Traduzido por Ana Carolina Eiras Coelho Soares. Projeto História: Revista do Programa de Estudos PósGraduados de História, 45, 2014.

https://revistas.pucsp.br/revph/article/view/15018 Acesso em junho de 2020

SILVA, Tânia Maria Gomes da. Trajetória da Historiografia das Mulheres no Brasil. Rev. Politeia, Vitória da Conquista, v. 8, n.1, p. 223-231, 2008.

SIMPATIA, Tião, A lei Maria da Penha em Cordel. Texto Tião Simpatia; lustrações Meg Banhos. Fortaleza. Armazém da Cultura, 2011. 


\section{HISTÓRIA}

Dossiê: Ensino de História, História das Mulheres e Desigualdades Sociais no Brasil

SOARES, Ana Carolina Eiras Coelho. (2015) Feminilidade. IN: COLLING, Ana Maria; TEDESCHI, Losandro A. Dicionário Crítico de Gênero. Dourados: EdUFGD.

VEIGA, Ilma Passos Alencar. Licenciatura em pedagogia: Realidades, Incertezas, Utopias. Campinas, São Paulo: Papirus, 1997.

YUS, Rafael. Educação Integral: uma educação holística para o século XXI. Trad. Daisy Vaz de Moraes. - Porto Alegre: Artmed, 2002. 